\title{
Serological assessment of gastric mucosal atrophy in gastric cancer
}

\author{
Jan Bornschein ${ }^{1}$, Michael Selgrad ${ }^{1}$, Thomas Wex ${ }^{1}$, Doerthe Kuester ${ }^{2}$ and Peter Malfertheiner ${ }^{1 *}$
}

\begin{abstract}
Background: Non-invasive tools for gastric cancer screening and diagnosis are lacking. Serological testing with the detection of pepsinogen 1 (PG1), pepsinogen 2 (PG2) and gastrin 17 (G17) offers the possibility to detect preneoplastic gastric mucosal conditions. Aim of this study was to assess the performance of these serological tests in the presence of gastric neoplasia.

Methods: Histological and serological samples of 118 patients with gastric cancer have been assessed for tumor specific characteristics (Laurén type, localisation), degree of mucosal abnormalities (intestinal metaplasia, atrophy) and serological parameters (PG1, PG2, PG1/2-ratio, G17, H. pylori lgG, CagA status). Association of the general factors to the different serological values have been statistically analyzed.

Results: Patients with intestinal type gastric cancer had lower PG1 levels and a lower PG1/2-ratio compared to those with diffuse type cancer $(p=0.003)$. The serum levels of PG2 itself and G17 were not significantly altered. $H$. pylori infection in general had no influence on the levels of PG1, PG2 and G17 in the serum of gastric cancer patients. There was a trend towards lower PG1 levels in case of positive CagA-status $(p=0.058)$. The degree of both intestinal metaplasia and atrophy correlated inversely with serum levels for PG1 and the PG1/2-ratio ( $p<$ 0.01). Laurén-specific analysis revealed that this is only true for intestinal type tumors. Univariate ANOVA revealed atrophy and CagA-status as the only independent factors for low PG1 and a low PG1/2-ratio.
\end{abstract}

Conclusions: Glandular atrophy and a positive CagA status are determinant factors for decreased pepsinogen 1 levels in the serum of patients with gastric cancer. The serological assessment of gastric atrophy by analysis of serum pepsinogen is only adequate for patients with intestinal type cancer.

Keywords: Gastric cancer, Helicobacter pylori, intestinal metaplasia, glandular atrophy, gastrin, pepsinogen, cardia cancer

\section{Background}

Most of the patients report only a short period of symptoms appearing before the establishment of the first diagnosis of gastric cancer (GC). Up to $40 \%$ report not to have any dyspeptic symptoms at all [1]. The prognosis is dismal in most cases, and therefore, an adequate and cost-effective screening program to enable early detection of the disease is needed to reduce gastric cancer-related mortality [2]. Population mass screening for $\mathrm{GC}$ has only been conducted in high incidence regions

\footnotetext{
* Correspondence: peter.malfertheiner@med.ovgu.de

'Department of Gastroenterology, Hepatology and Infectious Diseases, Ottovon-Guericke-University of Magdeburg, Leipziger Str. 44, D-39120 Magdeburg, Germany

Full list of author information is available at the end of the article
}

in Asia with good results by lowering the mortality from GC in Korea and Japan [3,4].

Endoscopy with sampling of gastric biopsies was documented as the best and most effective option for screening for upper GI malignancies [4]. Based on retrospective data from Singapore it has been estimated that endoscopic screening for stomach cancer can be cost-effective only in moderate to high-risk populations [5]. Thus, endoscopic screening is not applicable in low risk regions and therefore non-invasive screening modalities are needed in these populations. In the absence of reliable biomarkers for the detection of gastric cancer, a screening program would include the evaluation of surrogate markers such as the detection of Helicobacter

\section{Biomed Central}


pylori (H. pylori), and the serological characterization of preneoplastic conditions of the gastric mucosa.

This concept fits best to the intestinal type of GC with the well described progression from $H$. pylori driven chronic gastritis via atrophic gastritis, intestinal metaplasia (IM) and intraepithelial neoplasia (formerly called dysplasia) to invasive gastric cancer [6]. At a lower prevalence, gastric atrophy and IM are also reported in association with diffuse type carcinomas [7]. Glandular atrophy in the body can be regarded as premalignant condition [8], and the risk for gastric carcinogenesis has been reported to be increased and correlated with the degree of baseline atrophy [9]. For non-invasive detection and grading of gastric atrophy pepsinogen I (PG1), pepsinogen II (PG2), and gastrin 17 (G17) in the serum are suitable parameters [10-12].

In a meta-analysis evaluating more than 40 studies with about 300,000 individuals included, Miki and colleagues reported that tests on serum pepsinogens are not appropriate for GC screening but may be useful for identification of high-risk individuals who necessitate further diagnostic work-up [13]. These conclusions were confirmed by recent studies [14-17].

The serological analysis for $H$. pylori-infection should be included in further analyses [18], since the presence of $H$. pylori can increase the risk for gastric carcinogenesis independently from the presence of mucosal atrophy $[16,17]$.

So far, there was no success to include the available data in the algorithms for serological gastric cancer screening. The aim of the present study was to evaluate the association of specific gastric cancer characteristics and the H. pylori status in combination with the serum levels of PG1, PG2 and G17. Since it was not aim of the study to assess the diagnostic value of these tests general but the confounding influence of gastric cancer we did not include the evaluation of a healthy control group.

\section{Methods}

Patients with GC were enrolled in the course of a different study that was approved by the local ethic committee. Written informed consent was obtained. The available material was re-evaluated for the presence of $H$. pylori infection, including CagA status, and histopathological mucosal alterations. The groups were analyzed according to their histopathological type of carcinoma (i.e. intestinal vs. diffuse type by Laurén) and the location of the primary tumor. Serum samples were assessed for the content of gastrin 17 (G17), pepsinogen 1 (PG1) and pepsinogen 2 (PG2). These analyses have been performed in concordance with the guidelines of the local ethics committee.

\section{Data assessment}

Patients' data was verified using the electronic patient documentation system of the Department of Gastroenterology,
Hepatology and Infectious Diseases at the University Hospital of Magdeburg, Germany. Patients were included in case of complete records and availability of adequately stored serum samples for serological analysis $\left(-80^{\circ} \mathrm{C}\right)$. In total, 118 patients met these criteria.

Only patients with either intestinal $(n=59)$ or diffuse type tumors $(n=59)$ according to the Laurén classification were included for further analysis, mixed type tumors were excluded $(n=12)$. Exclusion of mixed type tumors was done to analyse only clearly distinct tumor entities. Since "Laurén type" was considered as a potential confounding factor for the serological tests, we aimed for a strict comparison between intestinal and diffuse type gastric cancer.

Tumors were classified according to the location of the main tumor mass into carcinomas of the antrum, the corpus and the cardia. Cardia tumors were further subclassified according to the AEG-classification as proposed by Siewert and Stein in 1998 (AEG = adenocarcinoma of the esophagogastric junction) [19]. Supracardial carcinomas (AEG1) with a high likelihood of the distal esophagus being the site of origin have been excluded, as well as AEG2 with adjacent Barrett's mucosa. Tumors have been stratified into "proximal" and "distal" carcinomas of the stomach according to the location of the main tumor mass as described previously [7]. Tumors in the region of the esophagogastric junction were clearly classified as "proximal" and antrum-tumors as "distal". The group of corpus-carcinomas was subdivided. Carcinomas with the main tumor mass in the fundus and in the proximal third of the corpus were classified as "proximal", all more distally located corpus carcinomas (lower two thirds) as "distal".

Tumor allocation was assessed either by the primary endoscopy report including endoscopic ultrasound or by the pathological report of the resected specimen in case of gastrectomy. This classification of tumor allocation was chosen by convention of the authors. Tumor allocation was stratified prospectively to any statistical analysis.

\section{Histopathological assessment}

Histopathological alterations of the gastric mucosa (IM and glandular atrophy) were assessed according to the updated Sydney system [20].

Biopsies had been taken in duplicate from the prepyloric antrum and the corpus (lesser and greater curvature). Cardia-derived samples were obtained directly below the Z-Line at the proximal end of the gastric folds. Additional samples were taken from the tumor itself and in some cases from the surrounding mucosa.

Biopsies were processed by routine methods. One section was stained with hematoxilin and eosin, modified Giemsa for detection of H. pylori, and PAS stain. 
In patients that were referred to our hospital for gastrectomy with no further endoscopic examination being performed, histology was assessed on the surgical specimen.

\section{Assessment of serum parameters}

Serum was prepared from 5-7 $\mathrm{ml}$ venous blood by centrifugation at $7.000 \mathrm{x} \mathrm{g}$ at $4{ }^{\circ} \mathrm{C}$ for $15 \mathrm{~min}$, aliquoted in three individual cryotubes (each 1-1.5 ml) within 3 hours after taking blood. Samples were stored at $-80^{\circ} \mathrm{C}$ until analysis. The concentration of anti-H. pylori IgG antibodies were analyzed using the Pyloriset EIA-G III (Orion Diagnostica, Finland) according to the manufacturer's instructions. According to the validation of the kit, a positive result was defined as $\geq 30 \mathrm{EIU}$, a negative result as < 30 EIU. The prevalence of anti-CagA antibodies was investigated using undiluted sera and the Helicobacter pylori Vira blot test kit (Viramed Biotech AG, Lich, Germany) according to the instructions by the manufacturer. Patients with positive CagA-status were classified as " $H$. pylori positive" even when anti-H. pylori IgG was below the cut-off level also including patients with "a serological scar". It has to be mentioned that by this definition not only patients with actual infection were classified as $H$. pylori-positive, but also patients with prior eradication therapy or those in which bacteria have disappeared during the progression of histological alterations. Since the so-called "point of no return" from which on eradication cannot prevent further progression of premalignant conditions is not defined yet, we believe that inclusion of all patients with a past history of $H$. pylori infection is justified.

The analyses of anti-H. pylori IgG antibodies and PG1, PG2 and G17 (Gastrin-17 EIA Test Kit, Pepsinogen-I, Pepsinogen-II EIA Test Kit, Biohit Plc, Finland) was performed at the same aliquot and as described by the manufacturer.

\section{Statistical analysis}

Group comparison was performed using Fisher's exact test, correlation analysis by Spearman's rank correlation test. The $\mathrm{t}$-test for independent samples was applied to assess the influence of age as a confounding factor and to compare the degree of mucosal alterations between groups. Group comparison concerning the serum values of G17, PG1 and PG2, as well as the PG-ratio have been performed by the Mann-Whitney U-test as well as univariate ANOVA for interference analysis. For all tests, a two-sided significance level of $P<0.05$ was assumed. Data were analyzed using SPSS 11.0 (SPSS Inc., Chicago, IL, USA).

\section{Results}

General characteristics of the study population

The general characteristics of the study population are described in table 1.

Patients with intestinal type tumors were significantly younger than those with diffuse type GC ( $p=0.029)$, and showed a higher proportion of female patients $(p=$ $0.037)$. There was no significant difference in the distribution of proximal and distal GC between the two Laurén types. However, there were more corpus carcinomas in the group with diffuse type GC ( $p=0.013)$. Both $H$. pylori and CagA status were similar between the two Laurén types. There was a higher prevalence for IM and glandular atrophy in case of intestinal type GC compared to diffuse type tumors $(p=0.002, p<0.001$, resp.). Table 2 gives an overview about for the distribution of mucosal changes in both Laurén types.

\section{Pepsinogens and G17 in the serum and pathobiological characteristics}

Patients with diffuse type GC presented with 1.56-fold higher PG1 levels compared to those with intestinal type tumors $(127.9 \mathrm{ng} / \mathrm{ml}$ vs. $81.9 \mathrm{ng} / \mathrm{ml})$. This difference was not statistically significant $(p=0.062$; additional file 1 ). Values of the PG1/2-ratio were significantly higher in case of diffuse type carcinomas (10.4 vs. $6.8 ; p=0.003$; table 1 ; additional file 2 ). There was no difference concerning the serum levels of G17 and PG2 between GC of the intestinal and diffuse type.

Generally, serum levels of PG1, PG2 and G17 were similar between $H$. pylori-positive and -negative subjects. A trend towards lower PG1 serum levels $(94.6 \mathrm{ng} / \mathrm{ml}$ vs. $141.6 \mathrm{ng} / \mathrm{ml} ; p=0.058)$ was observed for patients with positive CagA status compared to negative ones (table 1; additional file 1).

There was no difference in serum parameters between carcinomas with proximal and distal location.

Pepsinogens and G17 in the serum and mucosal changes Patients with presence of atrophy showed significantly lower levels of PG1 $(p<0.001)$ as well as a lower PG1/ 2 -ratio $(p>0.001)$ than those without atrophy (Table 3; additional file 2). This was confirmed for patients with intestinal type tumors for both PG1 $(p=0.003)$ and the PG1/2-ratio $(p=0.028)$.

Patients with IM in the stomach demonstrated both lower PG1 values $(p=0.02)$ and a lower PG1/2-ratio ( $p$ $=0.006$ ) than patients without metaplasia (additional file 2 ). Laurén specific comparison could confirm this result for PG1 levels in case of diffuse type carcinomas ( $p=$ 0.029). 
Table 1 General characteristics of the study population

\begin{tabular}{|c|c|c|c|c|c|c|c|}
\hline \multirow[b]{2}{*}{$\mathrm{Age}^{*}$} & \multirow[b]{2}{*}{ (mean \pm SD) } & \multicolumn{2}{|c|}{ Intestinal GC ( $n=59)$} & \multicolumn{2}{|c|}{ Diffuse GC ( $n=59)$} & \multicolumn{2}{|c|}{ Total $(n=118)$} \\
\hline & & $67.5 \pm 12.5$ & years & $62.2 \pm 13.6$ & years & $64.9 \pm 13.3$ & years \\
\hline Sex* & (female) & 42 & $71.2 \%$ & 30 & $50.8 \%$ & 72 & $61.0 \%$ \\
\hline H. pylori & (positive) & 50 & $84.7 \%$ & 49 & $83.1 \%$ & 99 & $83.9 \%$ \\
\hline \multirow[t]{2}{*}{ CagA } & (positive in total) & 39 & $66.1 \%$ & 38 & $64.4 \%$ & 77 & $65.3 \%$ \\
\hline & (of H.pylori-positive) & & $78.0 \%$ & & $77.6 \%$ & & $77.8 \%$ \\
\hline \multirow[t]{5}{*}{ Localisation* } & Cardia & 21 & $35.6 \%$ & 13 & $22.0 \%$ & 34 & $28.8 \%$ \\
\hline & Corpus & 21 & $35.6 \%$ & 37 & $62.7 \%$ & 58 & $49.2 \%$ \\
\hline & Antrum & 17 & $28.8 \%$ & 9 & $15.3 \%$ & 26 & $22.0 \%$ \\
\hline & Proximal & 30 & $50.8 \%$ & 23 & $39 \%$ & 53 & $44.9 \%$ \\
\hline & Distal & 29 & $49.2 \%$ & 36 & $61 \%$ & 65 & $55.1 \%$ \\
\hline Atrophy* & (positive) & 33 & $55.9 \%$ & 10 & $16.9 \%$ & 43 & $36.4 \%$ \\
\hline $\mathrm{IM}^{*}$ & (positive) & 51 & $86.4 \%$ & 35 & $59.3 \%$ & 86 & $72.9 \%$ \\
\hline PG1 & (median, range) & \multicolumn{2}{|c|}{$81.9(4.2-699.8) \mathrm{ng} / \mathrm{ml}$} & \multicolumn{2}{|c|}{$127.9(5.3-877.5) \mathrm{ng} / \mathrm{ml}$} & \multicolumn{2}{|c|}{$103.3(4.2-877.5) \mathrm{ng} / \mathrm{ml}$} \\
\hline PG2 & (median, range) & \multicolumn{2}{|c|}{$13.9(3.2-173.5) \mathrm{ng} / \mathrm{ml}$} & \multicolumn{2}{|c|}{$13.1(2.5-73.1) \mathrm{ng} / \mathrm{ml}$} & \multicolumn{2}{|c|}{$13.5(2.5-173.5) \mathrm{ng} / \mathrm{ml}$} \\
\hline PG-ratio* & (median, range) & \multicolumn{2}{|c|}{$6.8(0.4-25.8)$} & \multicolumn{2}{|c|}{$10.4(1.6-26.7)$} & \multicolumn{2}{|c|}{$8.3(0.4-26.7)$} \\
\hline G17 & (median, range) & \multicolumn{2}{|c|}{$13.8(0.1-220.0) \mathrm{pM}$} & \multicolumn{2}{|c|}{$12.8(0.6-194.2) \mathrm{pM}$} & \multicolumn{2}{|c|}{$13.4(0.1-220.0) \mathrm{pM}$} \\
\hline
\end{tabular}

Serum parameters are illustrated by median and range. Patients were regarded as "positive" for atrophy and IM if the Sydney-scaled degree of the mucosal alteration was $\geq 1$. Significant differences between intestinal and diffuse type GC are marked with an asterisk $\left(^{*}\right)$ applying a two-sided significance level of $p<$ 0.05 .

There was no significant influence of the mucosal changes on the absolute levels of PG2 and G17 in the serum.

Serum levels of PG1 correlated inversely with the degree of gastric glandular atrophy $(p<0.001 ; r=$ -0.385). This relation was also demonstrated for the PG1/2-ratio ( $p=0.001 ; r=-0.344)$ (additional file 3). According to the updated Sydney-classification, mucosal changes have been graded independently for antrum and corpus. Location-specific correlation-analyses revealed similar results for patients with atrophic foci in the antrum and the corpus (data not shown).

PG1 $(p<0.001, r=-0.351)$ and the PG1/2-ratio $(p=$ $0.002 ; r=-0.285)$ correlated inversely with the degree of IM (additional file 3). Subgroup analysis did not show

Table 2 Degree of atrophy and IM according to the updated Sydney-classification

\begin{tabular}{lllll}
\hline & & $\begin{array}{l}\text { Intestinal GC } \\
(\mathbf{n}=\mathbf{5 9})\end{array}$ & $\begin{array}{l}\text { Diffuse GC } \\
(\mathbf{n}=\mathbf{5 9})\end{array}$ & $\begin{array}{l}\text { Total } \\
(\mathbf{n}=\mathbf{1 1 8})\end{array}$ \\
\hline Atrophy & Antrum* & $0.71 \pm 0.83$ & $0.21 \pm 0.58$ & $0.47 \pm 0.76$ \\
& Corpus* $^{*}$ & $0.64 \pm 0.83$ & $0.29 \pm 0.65$ & $0.47 \pm 0.77$ \\
& Total* $^{*}$ & $0.90 \pm 0.87$ & $0.32 \pm 0.68$ & $0.61 \pm 0.83$ \\
\hline $\mathrm{IM}$ & Antrum* $^{*}$ & $1.32 \pm 0.83$ & $0.69 \pm 0.72$ & $1.01 \pm 0.84$ \\
& Corpus* $^{*}$ & $0.91 \pm 0.88$ & $0.51 \pm 0.73$ & $0.71 \pm 0.83$ \\
& Total* $^{*}$ & $1.47 \pm 0.82$ & $0.80 \pm 0.76$ & $1.14 \pm 0.86$ \\
\hline
\end{tabular}

Displayed are mean and standard deviation for the Sydney-scaled degree of glandular atrophy and IM for each antrum and corpus (for "total", the highest score of both localisations was counted). Significant differences between intestinal and diffuse type GC are marked with an asterisk $\left(^{*}\right)$ applying a twosided significance level of $p<0.05$. any difference between IM in antrum and corpus (data not shown).

There was no correlation of absolute serum values for PG2 with the degree of any mucosal alteration. G17 showed an inverse correlation with the degree of IM (not with atrophy) in the antrum ( $p=0.044 ; r=-0.191$; data not shown).

Both the degree of IM and the degree of atrophy correlated with the patients' age (IM: $p<0.001, r=0.341$; atrophy: $p=0.003, r=0.272$ ) (additional file 4 ).

All parameters mentioned above (Laurén type, localisation, IM, atrophy, H. pylori status, CagA status) have been evaluated by univariate ANOVA-analysis. Only the presence of atrophy $(p=0.022)$ and a positive CagA status $(p=0.013)$ had an influence on the serum levels of PG1. For none of the parameters analysed a significant influence on the PG1/2-ratio could be identified. Age was respected in this analysis but did not show an influence.

\section{Subgroup characteristics in case of pathological pepsinogen test}

To analyse the subgroup characteristics of patients with pathological pepsinogen test, a cut-off below $70 \mu \mathrm{g} / \mathrm{ml}$ for PG1 in the serum, as well as a cut-off below 3.0 for the PG1/2-ratio was defined as pathological. Patients with positive pepsinogen serum test showed a higher prevalence of glandular atrophy ( $p=0.003$ and 0.022 , respectively). Differences in further parameters did not show statistical significance. Please see table 4 for details. 
Table 3 PG1 in the serum and the PG1/2-ratio in association to gastric mucosal alterations

\begin{tabular}{|c|c|c|c|c|c|c|}
\hline & \multicolumn{2}{|c|}{ Intestinal GC ( $n=59)$} & \multicolumn{2}{|c|}{ Diffuse GC ( $n=59)$} & \multicolumn{2}{|l|}{ Total $(n=118)$} \\
\hline & PG1 (ng/ml) & PG1/2-ratio & PG1 (ng/ml) & PG1/2-ratio & PG1 (ng/ml) & PG1/2-ratio \\
\hline \multicolumn{7}{|l|}{ Atrophy } \\
\hline (pos. vs. neg.) & 50.4 vs. $120.6^{*}$ & 4.4 vs. $8.1^{*}$ & 77.9 vs. 141.6 & 7.0 vs. 11.0 & 56.2 vs. $136.6^{*}$ & 5.0 vs. $10.4^{*}$ \\
\hline \multicolumn{7}{|l|}{ IM } \\
\hline (pos. vs. neg.) & 85.6 vs. 80.2 & 7.0 vs. 5.6 & 87.6 vs. $159.5^{*}$ & 8.4 vs. 11.5 & 86.3 vs. $147.8^{*}$ & 7.5 vs. $10.4^{*}$ \\
\hline
\end{tabular}

Displayed are medians of PG1 in the serum and of the PG1/2-ratio for patients with intestinal type and diffuse type GC as well as for the whole study population (range not shown). For each line values for patients with and without atrophy or IM are given in direct comparison. Significant differences are marked with an asterisk applying a two-sided significance level of $p<0.05$.

\section{Discussion}

\section{General aspects}

In the present study, we confirmed that gastric mucosal atrophy and a positive $H$. pylori CagA status are the determinant factors for low pepsinogen levels of patients with gastric cancer. The pepsinogen test for mucosal atrophy is not valid in patients with diffuse type gastric cancer.

The low incidence of glandular atrophy in our population is mainly due to the strict diagnostic criteria as mentioned in the methods section and is in line with data in the literature [21]. It has to be mentioned that we preferred applying the updated Sydney classification over more recently suggested staging systems for gastric mucosal alterations like OLGA or OLGIM $[22,23]$. The latter systems are still under evaluation in clinical practice and the Sydney-scaled assessment is widely accepted.

\section{Serum pepsinogens and mucosal changes}

Our data confirm the general association between gastric atrophy and decreased PG1 levels in the serum as well as a decreased PG1/2-ratio [13]. The same is seen in case of IM in the stomach which can partly be explained by the strong association between the presence of IM and atrophy. The consistence of our data is confirmed by the inverse correlation between the degree of both atrophy and IM and the serum levels of PG1 and the PG1/2-ratio which has been previously reported [24].

Variable cut-off-values for PG1 and the PG-ratio were applied in former studies [25], but levels below $70 \mu \mathrm{g} /$ $\mathrm{ml}$ and 3.0, respectively, found most acceptance resulting in a sensitivity of $66.7-84.6 \%$ and a specificity of $73.5-87.1 \%$ for the detection of atrophic gastritis [12,26-28]. Although some authors presented similar values for the detection of GC [27-29], especially the sensitivity for GC screening is significantly lower (36.8\%-62.3\%) compared to the assessment of gastric atrophy $[15,30,31]$. In our study, patients with a pathological pepsinogen-test revealed a prevalence of mucosal atrophy that was twice as high as in patients with normal serum pepsinogens.

\section{Serum pepsinogens and gastric cancer}

It has been reported recently, that the results of the PGtest method are independent from the Laurén type [32]. In the present study, only for the PG1/2-ratio a significant difference between intestinal and diffuse type carcinomas was documented which was reported by other authors $[7,33]$. However, in patients with diffuse type $\mathrm{GC}$ pepsinogen values in the serum gave no adequate information about the presence and degree of mucosal atrophy. There was no significant difference neither for PG1 nor for the PG-ratio between patients with and without atrophy. This could be an effect of the low

Table 4 Subgroup characteristics of patients with pathological pepsinogen test

\begin{tabular}{|c|c|c|c|c|c|c|c|}
\hline & & \multicolumn{2}{|c|}{$\mathrm{PG} 1<70 \mu \mathrm{g} / \mathrm{ml}$} & \multicolumn{4}{|c|}{ PG1/2-ratio < 3.0} \\
\hline & & Positive $(n=47)$ & Negative $(n=71)$ & $p$-value & Positive $(n=20)$ & Negative $(n=98)$ & $p$-value \\
\hline \multirow[t]{2}{*}{ Laurén type } & Intestinal & $28(59.6 \%)$ & $31(43.7 \%)$ & n.s. & 14 (70\%) & 45 (45.9\%) & n.s. \\
\hline & Diffuse & 19 (40.4\%) & $40(56.3 \%)$ & & $6(30 \%)$ & $53(54.1 \%)$ & \\
\hline \multirow[t]{2}{*}{ Localisation } & Proximal & $19(40.4 \%)$ & $34(47.9 \%)$ & n.s. & $11(55 \%)$ & $42(42.9 \%)$ & n.s. \\
\hline & Distal & $28(59.6 \%)$ & $37(52.1 \%)$ & & $9(45 \%)$ & $56(57.1 \%)$ & \\
\hline H. pylori & (positive) & $40(85.1 \%)$ & $59(83.1 \%)$ & n.s. & $17(85 \%)$ & $82(83.7 \%)$ & n.s. \\
\hline CagA & (positive) & $34(72.3 \%)$ & $43(60.6 \%)$ & n.s. & $15(75 \%)$ & $62(63.3 \%)$ & n.s. \\
\hline $\mathrm{IM}$ & (positive) & 39 (83.0\%) & $47(66.2 \%)$ & 0.057 & $16(80 \%)$ & 70 (71.4\%) & n.s. \\
\hline Atrophy* & (positive) & $25(53.2 \%)$ & $18(25.4 \%)$ & 0.003 & $12(60 \%)$ & $31(31.6 \%)$ & 0.022 \\
\hline
\end{tabular}

Displayed are absolute numbers as well as percentages with respect to the group with the same test result (PG test positive or negative). Significant differences are marked with an asterisk applying a two-sided significance level of $p<0.05$. 
prevalence of IM and atrophy in patients with diffuse type GC. Another explanation might be the diffuse infiltration of teh gastric mucosa by malignant tissue formations.

Serum analysis of PG1, PG2 and G17 can yield information about the distribution of IM and atrophy in the stomach [11,29]. It is still under debate if the location of a gastric adenocarcinoma has a significant influence on the results of these serological tests. Pepsinogen serum values are not different between patients with proximal and distal GC [32,34-38]. But previous studies showing no association to cardia cancer lack of a precise distinction between adenocarcinoma of the distal esophagus and proximal GC with only the latter being associated to chronic atrophic changes [31,39].

According to the updated Sydney-system the degree of glandular atrophy and IM was scaled separately for each antrum and corpus. Each localisation was evaluated separately in addition to the overall evaluation. The results of these analyses were similar so that location dependent bias is excluded in our study.

\section{Serum pepsinogens and $\mathrm{H}$. pylori}

The influence of H. pylori infection on serum pepsinogens was mostly evaluated in patients without gastric malignancy. The altered pepsinogen levels were interpreted as reaction to the inflammation process $[11,18,40,41]$. In the present study, only carriers of the more aggressive CagA-positive strains of $H$. pylori were affected in their PG1-levels. This influence is in line with studies that investigated risk-factor patterns that are associated with more progressive gastric disease [42]. It has been shown, that a positive CagA status is an independent risk factor that increases the $H$. pylori related odds ratio for the development of chronic atrophic gastritis $[43,44]$. The CagA antigen as major trigger of the inflammatory response might have a further influence on pepsinogen levels at different stages of mucosal transition, even without overt histopathological changes. It has been demonstrated that the CagA status is an individual indicator for atrophic changes in the gastric mucosa independent from pepsinogen levels in the serum $[21,30,45,46]$. Concerning the effect of $H$. pylori itself on the pepsinogen tests, a statistical bias cannot be excluded since $83.9 \%$ of the study population were $H$. pylori positive compared to only $16.1 \% \mathrm{H}$. pylori negatives.

The influence of CagA was confirmed by the univariate ANOVA-test analysing the influence of the pathobiological characteristics on the pepsinogen values. Besides the presence of atrophic changes only a positive CagA status revealed an independent influence on PG1 levels in the serum. Laurén type and location of the tumor have no influence on the serum-pepsinogen tests as reported before [47].
It is notable that in the present study $H$. pylori status was assessed only by serum-based methods. Therefore, not only patients with actual $H$. pylori infection were classified as $H$. pylori-positive but also patients with prior infection. It has been shown in studies on patients with atrophic gastritis that bacteria are cleared during the development of atrophy [48]. Thus, the infection cannot be detected anymore although the related histomorphological changes were initially caused by $H$. pylori-driven inflammation. Inclusion of patients with a "serological scar" of prior infection prevents underestimation of $H$. pylori-associated processes.

\section{Gastrin 17 and Pepsinogen 2}

G17 and absolute PG2 serum values were not influenced by GC-related factors. It has been reported, that PG2 is upregulated inflammation-dependent in case of $H$. pylori induced gastritis, whereas the data about more severe stages of gastric disease are scarce and only reflected by changes in the PG1/2-ratio $[11,31,45]$. A recent study on a population in Shanghai reported a three-fold increased risk for GC in case of PG2 levels above 6.6 $\mathrm{ng} / \mathrm{l}$ in the serum [34].

At the stage of gastritis with or without focal atrophic changes, G17-levels in the serum correlate not only with the degree of the mucosal damage but also with their location in the stomach. However, it is questionable if these associations can be transferred to the stage of invasive GC. Hansen et al. reported that there was no difference in G17-levels in patients with proximal and distal GC [34].

\section{Conclusion}

We confirmed that in patients with GC there is no independent association of serum levels for PG1, PG2 and G17 with the Laurén type nor with location of the main tumor mass. Serological assessment of PG1 and the PG1/2-ratio provides an adequate report on the severity of atrophic changes in the gastric mucosa in patients with intestinal type cancer. CagA is positively associated with a decrease of serum PG1 and the PG1/2-ratio.

The study confirms that a serological screening for preneoplastic conditions is possible. Therefore, these serological tests could help to identify individuals at high risk for further gastric cancer development even in regions with low incidence of gastric adenocarcinoma. In patients with an abnormally low serum pepsinogen test, upper gastrointestinal endoscopy should be performed and if premalignant conditions are confirmed these patients should be included in an endoscopic surveillance programme. This strategy has been recommended in a recently published consensus report on the managment of precancerous conditions and lesions in the stomach (MAPS) [49]. 
Serological screening can be offered in combination with other means of prevention like e.g. screening colonoscopy for colorectal cancer prevention. Prospective multicenter trials are necessary for analysis of cost-effectiveness of this strategy.

\section{Additional material}

Additional file 1: Figure s1: PG1 and the PG1/2-ratio according to Laurén type and CagA status. A) Patients with intestinal type GC presented lower values for both parameters. The difference was significant only for the PG1/2-ratio $(p=0.003)$ not for PG1 $(p=0.062)$. B) Patients with positive CagA status revealed a trend for lower PG1 levels ( $p=0.058)$ but no difference in the PG1/2-ratio compared to CagA negative individuals. Comparison was done by the Mann-Whitney U-test, significance for $p<0.05$

Additional file 2: Figure s2: PG1 and the PG1/2-ratio according to the presence of atrophy and IM. A) Patients with glandular atrophy presented lower values for PG1 $(p<0.001)$ and for the PG1/2-ratio $(p<$ $0.001)$. B) Patients with IM presented lower values for PG1 $(p=0.02)$ and for the PG1/2-ratio $(p=0.006)$. Comparison was done by the MannWhitney U-test, significance for $p<0.05$.

Additional file 3: Figure s3: Correlation of PG1 levels and PG-ratio with the degree of glandular atrophy and IM. A) For both PG1 ( $p<$ $0.001 ; r=-0.385)$ and the PG1/2-ratio $(p=0.001 ; r=-0.344)$ there was an inverse association to the degree of glandular atrophy. B) For both PG1 $(p<0.001 ; r=-0.351)$ and the PG1/2-ratio $(p=0.002 ; r=-0.285)$ there was an inverse association to the degree of IM. Analysis was done by Spearman's rank correlation test, significance for $p<0.05$.

Additional file 4: Figure s4: Correlation of patients' age with the degree of mucosal changes. Correlation of patients' age with A) atrophy $(p=0.003 ; r=0.341)$ and $\mathrm{B})$ with $\mathrm{IM}(p<0.001 ; r=0.272)$. Analysis was done by Spearman's rank correlation test $(p<0.05)$.

\section{Abbreviations}

AEG: adenocarcinoma of the esophagogastric junction; CagA: cytotoxic antigen $A$; G17: gastrin 17; GC: gastric cancer; H. pylori: Helicobacter pylori; IM: intestinal metaplasia; OLGA: operative link for gastritis assessment; OLGIM: operative link on gastric intestinal metaplasia assessment; PG1: pepsinogen I; PG2: pepsinogen II; PG-ratio: pepsinogen-ratio.

\section{Acknowledgements}

We thank Ursula Stolz and Marion Holley for their support of the study and the excellent work in the laboratory.

\section{Author details}

'Department of Gastroenterology, Hepatology and Infectious Diseases, Ottovon-Guericke-University of Magdeburg, Leipziger Str. 44, D-39120 Magdeburg, Germany. ${ }^{2}$ Department of Pathology, Otto-von-GuerickeUniversity of Magdeburg, Leipziger Str. 44, D-39120 Magdeburg, Germany.

\section{Authors' contributions}

JB did the main part of the data collection, performed the statistical analysis and drafted the manuscript. MS contributed to the data collection and helped to draft the manuscript. TW coordinated and performed the work done in the laboratory (serum analysis). DK provided the pathological data on gastric cancer characteristics and the scoring of gastritis according to the updated Sydney classification. PM as principal supervisor helped to design the study and reviewed the draft of the manuscript. All authors read and approved the final manuscript.

\section{Competing interests}

The authors declare that they have no competing interests.
Received: 29 September 2011 Accepted: 31 January 2012

Published: 31 January 2012

\section{References}

1. Schmidt N, Peitz U, Lippert $H$, Malfertheiner P: Missing gastric cancer in dyspepsia. Aliment Pharmacol Ther 2005, 1;21:813-820.

2. Yoshihara M, Hiyama T, Yoshida S, Ito M, Tanaka S, Watanabe Y, et al: Reduction in gastric cancer mortality by screening based on serum pepsinogen concentration: a case-control study. Scand J Gastroenterol 2007, 42:760-764.

3. Lee KJ, Inoue M, Otani T, Iwasaki M, Sasazuki S, Tsugane S: Gastric cancer screening and subsequent risk of gastric cancer: a large-scale population-based cohort study, with a 13-year follow-up in Japan. Int $J$ Cancer 2006, 1;118:2315-2321.

4. Tashiro A, Sano M, Kinameri K, Fujita K, Takeuchi Y: Comparing mass screening techniques for gastric cancer in Japan. World J Gastroenterol 2006, 14;12:4873-4874.

5. Dan YY, So JB, Yeoh KG: Endoscopic screening for gastric cancer. Clin Gastroenterol Hepatol 2006, 4:709-716.

6. Correa P: A human model of gastric carcinogenesis. Cancer Res 1988, 1:48:3554-3560.

7. Bornschein J, Selgrad M, Warnecke M, Kuester D, Wex T, Malfertheiner P: H. pylori Infection Is a Key Risk Factor for Proximal Gastric Cancer. Dig Dis Sci 2010, 55:3124-31.

8. Kamada T, Hata J, Sugiu K, Kusunoki H, Ito M, Tanaka S, et al: Clinical features of gastric cancer discovered after successful eradication of Helicobacter pylori: results from a 9-year prospective follow-up study in Japan. Aliment Pharmacol Ther 2005, 1;21:1121-1126.

9. Take S, Mizuno M, Ishiki K, Nagahara Y, Yoshida T, Yokota K, et al: Baseline gastric mucosal atrophy is a risk factor associated with the development of gastric cancer after Helicobacter pylori eradication therapy in patients with peptic ulcer diseases. J Gastroenterol 2007, 42(Suppl 17):21-27.

10. DiMario F, Moussa AM, Caruana P, Merli R, Cavallaro LG, Cavestro GM, et al: 'Serological biopsy' in first-degree relatives of patients with gastric cancer affected by Helicobacter pylori infection. Scand I Gastroenterol 2003, 38:1223-1227.

11. Cao Q, Ran ZH, Xiao SD: Screening of atrophic gastritis and gastric cancer by serum pepsinogen, gastrin-17 and Helicobacter pylori immunoglobulin G antibodies. J Dig Dis 2007, 8:15-22.

12. Leja $M$, Kupcinskas L, Funka $K$, Sudraba A, Jonaitis L, Ivanauskas $A$, et al: The validity of a biomarker method for indirect detection of gastric mucosal atrophy versus standard histopathology. Dig Dis Sci 2009, 54:2377-2384.

13. Miki K: Gastric cancer screening using the serum pepsinogen test method. Gastric Cancer 2006, 9:245-253.

14. Miki K, Fujishiro M, Kodashima S, Yahagi N: Long-term results of gastric cancer screening using the serum pepsinogen test method among an asymptomatic middle-aged Japanese population. Dig Endosc 2009, 21:78-81.

15. Mizuno S, Kobayashi M, Tomita S, Miki I, Masuda A, Onoyama M, et al: Validation of the pepsinogen test method for gastric cancer screening using a follow-up study. Gastric Cancer 2009, 12:158-163.

16. Mizuno S, Miki I, Ishida T, Yoshida M, Onoyama M, Azuma T, et al: Prescreening of a high-risk group for gastric cancer by serologically determined Helicobacter pylori infection and atrophic gastritis. Dig Dis Sci 2010, 55:3132-3137.

17. Zhang X, Xue L, Xing L, Wang J, Cui J, Mi J, et al: Low serum pepsinogen I and pepsinogen $\mathrm{I} / \mathrm{Il}$ ratio and Helicobacter pylori infection are associated with increased risk of gastric cancer: 14-year follow up result in a rural Chinese community. Int J Cancer 2011.

18. Watabe H, Mitsushima T, Yamaji Y, Okamoto M, Wada R, Kokubo T, et al Predicting the development of gastric cancer from combining Helicobacter pylori antibodies and serum pepsinogen status: a prospective endoscopic cohort study. Gut 2005, 54:764-768.

19. Siewert J, Stein HJ: Classification of adenocarcinoma of the oesophagogastric junction. Br J Surg 1998, 85:1457-1459.

20. Dixon MF, Genta RM, Yardley JH, Correa P: Classification and grading of gastritis. The updated Sydney System. International Workshop on the Histopathology of Gastritis, Houston 1994. Am J Surg Pathol 1996, 20:1161-1181.

21. So JB, Yeoh KG, Moochala S, Chachlani N, Ho J, Wong WK, et al: Serum pepsinogen levels in gastric cancer patients and their relationship with 
Helicobacter pylori infection: a prospective study. Gastric Cancer 2002, 5:228-232.

22. Capelle LG, de Vries AC, Haringsma J, Ter BF, de Vries RA, Bruno MJ, et al: The staging of gastritis with the OLGA system by using intestinal metaplasia as an accurate alternative for atrophic gastritis. Gastrointest Endosc 2010, 71:1150-8.

23. Rugge M, Meggio A, Pennelli G, Piscioli F, Giacomelli L, De PG, et al: Gastritis staging in clinical practice: the OLGA staging system. Gut 2007 56:631-636.

24. Pasechnikov VD, Chukov SZ, Kotelevets SM, Mostovov AN, Mernova VP, Polyakova MB: Possibility of non-invasive diagnosis of gastric mucosal precancerous changes. World J Gastroenterol 2004, 1;10:3146-3150.

25. Brenner $H$, Rothenbacher D, Weck MN: Epidemiologic findings on serologically defined chronic atrophic gastritis strongly depend on the choice of the cutoff-value. Int J Cancer 2007, 15;121:2782-2786.

26. Hattori $Y$, Tashiro H, Kawamoto $T$, Kodama Y: Sensitivity and specificity of mass screening for gastric cancer using the measurment of serum pepsinogens. Jpn J Cancer Res 1995, 86:1210-1215.

27. Kikuchi S, Kato M, Katsuyama T, Tominaga S, Asaka M: Design and planned analyses of an ongoing randomized trial assessing the preventive effect of Helicobacter pylori eradication on occurrence of new gastric carcinomas after endoscopic resection. Helicobacter 2006, 11:147-151.

28. Kitahara F, Kobayashi K, Sato T, Kojima Y, Araki T, Fujino MA: Accuracy of screening for gastric cancer using serum pepsinogen concentrations. Gut 1999, 44:693-697.

29. Shiotani A, lishi $H$, Uedo $N$, Kumamoto $M$, Nakae $Y$, Ishiguro $S$, et al: Histologic and serum risk markers for noncardia early gastric cancer. Int J Cancer 2005, 20;115:463-469.

30. Yanaoka K, Oka M, Mukoubayashi C, Yoshimura N, Enomoto S, Iguchi M, et al: Cancer high-risk subjects identified by serum pepsinogen tests: outcomes after 10-year follow-up in asymptomatic middle-aged males. Cancer Epidemiol Biomarkers Prev 2008, 17:838-845.

31. Kang JM, Kim N, Yoo JY, Park YS, Lee DH, Kim HY, et al: The role of serum pepsinogen and gastrin test for the detection of gastric cancer in Korea. Helicobacter 2008, 13:146-156.

32. Kwak MS, Kim N, Lee HS, Lee HE, Jung HC, Song IS: Predictive power of serum pepsinogen tests for the development of gastric cancer in comparison to the histologic risk index. Dig Dis Sci 2010, 55:2275-2282.

33. Boussioutas A, Li H, Liu J, Waring P, Lade S, Holloway AJ, et al: Distinctive patterns of gene expression in premalignant gastric mucosa and gastric cancer. Cancer Res 2003, 15;63:2569-2577.

34. Hansen S, Vollset SE, Derakhshan MH, Fyfe V, Melby KK, Aase S, et al: Two distinct aetiologies of cardia cancer; evidence from premorbid serological markers of gastric atrophy and Helicobacter pylori status. Gut 2007, 56:918-925.

35. Ren JS, Kamangar F, Qiao YL, Taylor PR, Liang H, Dawsey SM, et al: Serum pepsinogens and risk of gastric and oesophageal cancers in the General Population Nutrition Intervention Trial cohort. Gut 2009, 58:636-642.

36. Knekt $P$, Teppo L, Aromaa A, Rissanen H, Kosunen TU: Helicobacter pylori $\lg A$ and $\lg G$ antibodies, serum pepsinogen I and the risk of gastric cancer: changes in the risk with extended follow-up period. Int J Cancer 2006, 1;119:702-705.

37. Ye W, Held M, Lagergren J, Engstrand L, Blot WJ, McLaughlin JK, et al: Helicobacter pylori infection and gastric atrophy: risk of adenocarcinoma and squamous-cell carcinoma of the esophagus and adenocarcinoma of the gastric cardia. J Natl Cancer Inst 2004, 3;96:388-396.

38. Derakhshan MH, Malekzadeh R, Watabe H, Yazdanbod A, Fyfe V, Kazemi A, et al: Combination of gastric atrophy, reflux symptoms and histological subtype indicates two distinct aetiologies of gastric cardia cancer. Gut 2008, 57:298-305.

39. Sun $L P$, Gong $Y H$, Wang $L$, Yuan $Y$ : Serum pepsinogen levels and their influencing factors: a population-based study in 6990 Chinese from North China. World J Gastroenterol 2007, 28;13:6562-6567.

40. Rembiasz K, Konturek PC, Karcz D, Konturek SJ, Ochmanski W, Bielanski W, et al: Biomarkers in various types of atrophic gastritis and their diagnostic usefulness. Dig Dis Sci 2005, 50:474-482.

41. Palli D, Masala G, Del GG, Plebani M, Basso D, Berti D, et al: CagA+ Helicobacter pylori infection and gastric cancer risk in the EPIC-EURGAST study. Int J Cancer 2007, 120:859-867.

42. Adamu MA, Weck MN, Rothenbacher D, Brenner H: Incidence and risk factors for the development of chronic atrophic gastritis: Five year follow-up of a population-based cohort study. Int J Cancer 2011, 1;128:1652-1658

43. Con SA, Con-Wong R, Con-Chin GR, Con-Chin VG, Takeuchi H, Valerin AL, et al: Serum pepsinogen levels, Helicobacter pylori CagA Status, and cytokine gene polymorphisms associated with gastric premalignant lesions in Costa Rica. Cancer Epidemiol Biomarkers Prev 2007, 16:2631-2636.

44. Batista SA, Rocha GA, Rocha AM, Saraiva IE, Cabral MM, Oliveira RC, et al: Higher number of Helicobacter pylori CagA EPIYA C phosphorylation sites increases the risk of gastric cancer, but not duodenal ulcer. BMC Microbiol 2011, 24;11:61.

45. Haj-Sheykholeslami A, Rakhshani N, Amirzargar A, Rafiee R, Shahidi SM, Nikbin B, et al: Serum pepsinogen I, pepsinogen II, and gastrin 17 in relatives of gastric cancer patients: comparative study with type and severity of gastritis. Clin Gastroenterol Hepatol 2008, 6:174-179.

46. Xie XF, Ito M, Yoshihara M, Haruma K, Tanaka S, Chayama K: Serum pepsinogen levels in the Japanese population: prospective study of 9 years of follow-up. Hepatogastroenterology 2007, 54:1887-1890.

47. Abnet CC, Zheng W, Ye W, Kamangar F, Ji BT, Persson C, et al: Plasma pepsinogens, antibodies against Helicobacter pylori, and risk of gastric cancer in the Shanghai Women's Health Study Cohort. Br J Cancer 2011 26;104:1511-1516.

48. D'Elios MM, Appelmelk BJ, Amedei A, Bergmann MP, Del Prete G: Gastric autoimmunity: the role of Helicobacter pylori and molecular mimicry. Trends Mol Med 2004, 10;7:316-323.

49. Dinis-Ribeiro M, Areia M, deVries AC, Marcos-Pinto R, Monteiro-Soares M, O'Connor A, et al: Management of precancerous conditions and lesions in the stomach (MAPS): guidelinefrom the European Society of Gatsrointestinal Endoscopy (ESGE), European Helicobacter Study Group (EHSG), European Society of Pathology (ESP), and the Sociedade Portuguesa de Endoscopia Digestiva (SPED). Endoscopy 2012, 44:74-94.

\section{Pre-publication history}

The pre-publication history for this paper can be accessed here: http://www.biomedcentral.com/1471-230X/12/10/prepub

doi:10.1186/1471-230X-12-10

Cite this article as: Bornschein et al: Serological assessment of gastric mucosal atrophy in gastric cancer. BMC Gastroenterology 2012 12:10.

\section{Submit your next manuscript to BioMed Central and take full advantage of:}

- Convenient online submission

- Thorough peer review

- No space constraints or color figure charges

- Immediate publication on acceptance

- Inclusion in PubMed, CAS, Scopus and Google Scholar

- Research which is freely available for redistribution

Submit your manuscript at www.biomedcentral.com/submit
C Biomed Central 